\title{
Can we improve the quality of medical news merely by increasing journalists' health knowledge?
}

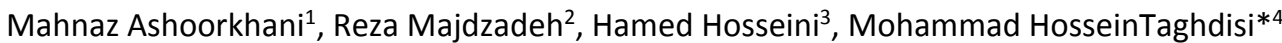

Received: 18 Aug $2018 \quad$ Published: 28 March 2019

\begin{abstract}
Background: The aim of this study was to determine the effectiveness of an educational intervention on the quality of health researchbased news, given the sensitivity of disseminating incorrect information.

Methods: An uncontrolled before-after study was conducted among health news producers in Tehran from November 2011 to March 2012. The intervention that included educational content in the form of a workshop was evaluated in advance. The outcome of measuring the scientific quality of news extracted from medical and health research results was considered for authenticity and accuracy. The health research-based news quality assessment tool was used. In this study, 32 individuals voluntarily entered the program, and their produced news was collected in 4 stages. To determine the effectiveness of the educational intervention, paired $t$ tests were used. SPSS version 17 was used for statistical analysis and $p<0.05$ was considered significant.

Results: The mean score $( \pm \mathrm{SD})$ of the participants' produced news was $0.40( \pm 0.089)$ before and $0.61( \pm 0.086)$ after the intervention, which increased by $0.21 \pm 0.09(\mathrm{p}<0.001)$. Of the news collected from the participants as baseline data, $544(65 \%)$ articles aimed at increasing public knowledge and awareness. Almost all the news had been gathered from interviews, and only 41 (4.8\%) news articles were based on health research results.

Conclusion: The educational intervention proved effective in promoting the quality of health research news. Only a few health journalists participated in this study, and thus the need to educate health news producers is felt. Since interviews with health researchers and experts were the largest source of news, interventions need to target other groups who affect the quality and accuracy of the news.
\end{abstract}

Keywords: Mass media, Journalism, Education, Intervention, Medical news

Conflicts of Interest: None declared

Funding: Tehran University of Medical Sciences

\section{*This work has been published underCC BY-NC-SA 1.0 license. \\ Copyright $\odot$ Iran University of Medical Sciences}

Cite this article as:Ashoorkhani M, Majdzadeh R, Hosseini H, Taghdisi MH. Can we improve the quality of medical news merely by increasing journalists' health knowledge?Med J Islam Repub Iran. 2019(28 March);33:24.https://doi.org/10.47176/mjiri.33.24

\section{Introduction}

Everyone likes to learn about scientific topics, especially those associated with health and medicine. The mass media play an important role in spreading health information. Various studies have shown that disseminated news can sometimes be of doubtful authenticity or inferior quality, and this has proven to be true in most of the re-

\section{Corresponding author: Dr Mohammad HosseinTaghdisi, taghdisi.mh@iums.ac.ir}

1. Knowledge Utilization Research Center (KURC) and Health Education \& Promotion Department, School of Public Health, Tehran University of Medical Sciences, Tehran, Iran

2. Community-Based Participatory-Research Center, Knowledge Utilization Research Center (KURC)and School of Public Health, Tehran University of Medical Sciences, Tehran, Iran

3. Center for Research and Training in Skin Diseases and Leprosy, Tehran University of Medical Sciences, Tehran, Iran

4. Health Education \& Promotion Department, , School of Public Health, Iran University of Medical Sciences, Tehran, Iran viewed countries (1-5). The public's trust in such news can be hazardous to their health (6).

Numerous factors at various levels affect the quality of health news. Some of these factors that affect the precision, authenticity, and quality of disseminated health news include the journalists' inadequate specialized knowledge

\section{$\uparrow$ What is "already known” in this topic:}

Nowadays, health research news has become popular. Dissemination of incorrect information, given its sensitivity, is of particular significance and needs to be addressed.

\section{$\rightarrow$ What this article adds:}

Education and empowerment of journalists can be useful in improving the quality of health research news. On the other hand, interviewing researchers has been the most important source of health news. Interactive tutorials between journalists and researchers are needed to improve the quality of health research news. 
of health research, limited writing space, disregarding the studies' evidences, exaggeration, difficulties in accessing the specialized sources of information, time limit for producing and publishing news for journalists, pressure from the editor-in-chief, policies, researchers' tendency to exaggerate the research findings, conflict of interests of stakeholders of organizations and institutions, difficulties in obtaining the opinions of health experts without organizational ties $(5,6)$, and the length of the news report and type of media (3).

It is important for news reports to be comprehensive, complete, and of high quality (1). In certain countries, measures have been taken to improve the quality of health news. Some of these measures and initiatives include websites such as media doctor, development and application of instructions for researchers and journalists $(1,7,8)$, and providing checklists for producing health news $(8,9)$.

Journalists' training could be considered as a solution to improve the quality of health news (10). Academic education on health and research subjects is essential for journalists who want to enter the domain of health journalism. Specialized training for journalists on methodology knowledge, research methodology, statistics, health domain, and access to reliable sources is truly inadequate (6). In fact, health journalists need to be introduced to the process of a medical investigation to be able to report accurately. In some developed countries, despite the attention of professional media that specialize in the training of journalists, still, they do not have enough access to such training (1).

Journalists are the most important health news producing community, and their level of health and research knowledge affects the quality of health news. In this study, it was tried to examine how the journalists and health news producers' educational program affects the quality of health research news. The educational program was designed according to the comprehensive checklist to prepare and control the health research-based news.

\section{Methods}

This single-arm trial study was performed from November 2011 to March 2012 in Tehran, and its main objective was to evaluate the effect of an educational intervention on health research news (HRN). This study has been registered in the Iranian Registry for Clinical Trial (IRCT2013012112211N1).

The participants were health news producers (journalists, translators, gatekeepers, and editors-in-chief working in the health field) who had been working in news agencies and publishing houses in the past 6 months (both private and public).

The applied intervention was in the form of an educational workshop where participants were taught how to prepare and write HRN. The educational content was prepared in advance and evaluated through a pilot phase.

\section{Educational content preparation process}

The following sources were used to prepare educational content on the production and preparation of health research news:
A) Target audience's expressed needs, as determined by the research team

B) Search for the existing literature

C) Topics in educational curricula of the academic, health, and media courses

D) Guides and checklists for preparing health research news

The topics mainly focused on the use of news production guides and HRN production checklists to make it more applicable, which included news sources' validity evaluation (scientific documentation, interviewee, and website), precision, avoiding social fear, significance of scientific findings in the news literature, magnitude of effect of results, identifying the main target audience of the news, consequences, consistency with other studies' results, complete characteristics of the news source, conflict of interests, consistency between the news headline and text, paying attention to the news level of complexity, and pointing out other treatment options and their availability.

The above-mentioned topics were presented as such in the content: general epidemiologic and statistic definitions, introduction to various health researches, various articles (along with description of their characteristics), introduction to different sections of an article and its features, and searching data banks.

The prepared content and applied educational technologies were examined by 5 epidemiologists and methodologists and5 education experts. The intervention was done through an educational workshop.

The content of the checklist was used to evaluate health researches. The methodologists and epidemiologists assessed and confirmed the educational contents.

The educational intervention was held as a pilot before the main phase to identify possible content issues, the chosen method of implementation, the method used for presentations and their order, timing of presented articles, and the use of individuals' feedbacks. An evaluator was present throughout the project. The participants' verbal and nonverbal feedbacks, certain details related to the tutors etc. were recorded. Based on the results of the pilot phase, the contents, timing, and presentations sequence were finalized for the main phase. The educational intervention was held as a 2-day workshop and ran for 6 hours each day.

\section{Measurements}

A) Baseline evaluation: During their registration, participants were asked to give the health news they had gathered in the 3 months prior to the workshop. Furthermore, the participants were given 11 articles, 8 research articles, 2 news stories from websites, and an interview a week before the workshop. Each participant had to arrange a news text and bring it along on the day of the workshop. Providing these 11 articles was a precondition for attending the workshop. The news was then evaluated using the Health Research News Quality Assessment Tool (9).The mean score of each news submitted by participants was considered as baseline data.

B) Evaluation immediately after the intervention: Two 
of the articles that were given to the participants before the intervention were handed out again. The produced news at this stage was evaluated using the same assessment tool.

C) Evaluation after 3 months: All of the health news that were produced by participants in the 3 months after the intervention were collected (Fig. 1).

\section{Sample size}

A sample size of 34 achieves $81 \%$ power to detect a mean of paired differences of 0.1 with an estimated standard deviation of differences of 0.1 and with a significance level (alpha) of0.05 using a 2-sided paired t-test.

The measured outcome was the scientific quality of HRN produced based on precision and authenticity and was measured by Health Research News Quality Assessment Tool, which contains 14 items (validity, precision, availability, prominence of scientific findings, magnitude, news headline, conflict of interests, applicability, consequences, level of complexity of the news report content, consistency, treatment options, providing the specifications of the news source and avoiding causing fear in the community) (9).

The final assessment of each news has the potential of obtaining a score between 0-14 that was reported as percentage of the total score. Scoring of the quality of news was done by the first author.

\section{Statistical analysis}

The study's quantitative variables, eg, quality of news produced by participants, were reported as mean and standard deviation (SD)and qualitative variables, eg, gender and level of education, were reported as frequency and percentage frequency. To estimate the main effect, the mean scores of Health Research News Quality were compared before and after the intervention $(95 \%$ confidence interval).

\section{Results}

A total of 34 individuals provided 11 articles to attend the workshop. Table 1 shows the participants' level of education and employment status. Five participants $(14.7 \%)$ were educated in health-related sciences, including medical, paramedical, and basic sciences.

From 840 news articles, 544 (65\%) were health-related and intended to raise the level of health and medical awareness and knowledge. Interviews were the source of $820(97.6 \%)$ produced news. Only $41(4.8 \%)$ cases of the collected news were related to research-based news (Table 2).

The result of this study showed that participants' news scores increased an average of 0.21 (95\% CI: -0.26 to 0.16 .) after the intervention program $(0.40$ and 0.61 before-after the intervention, respectively).

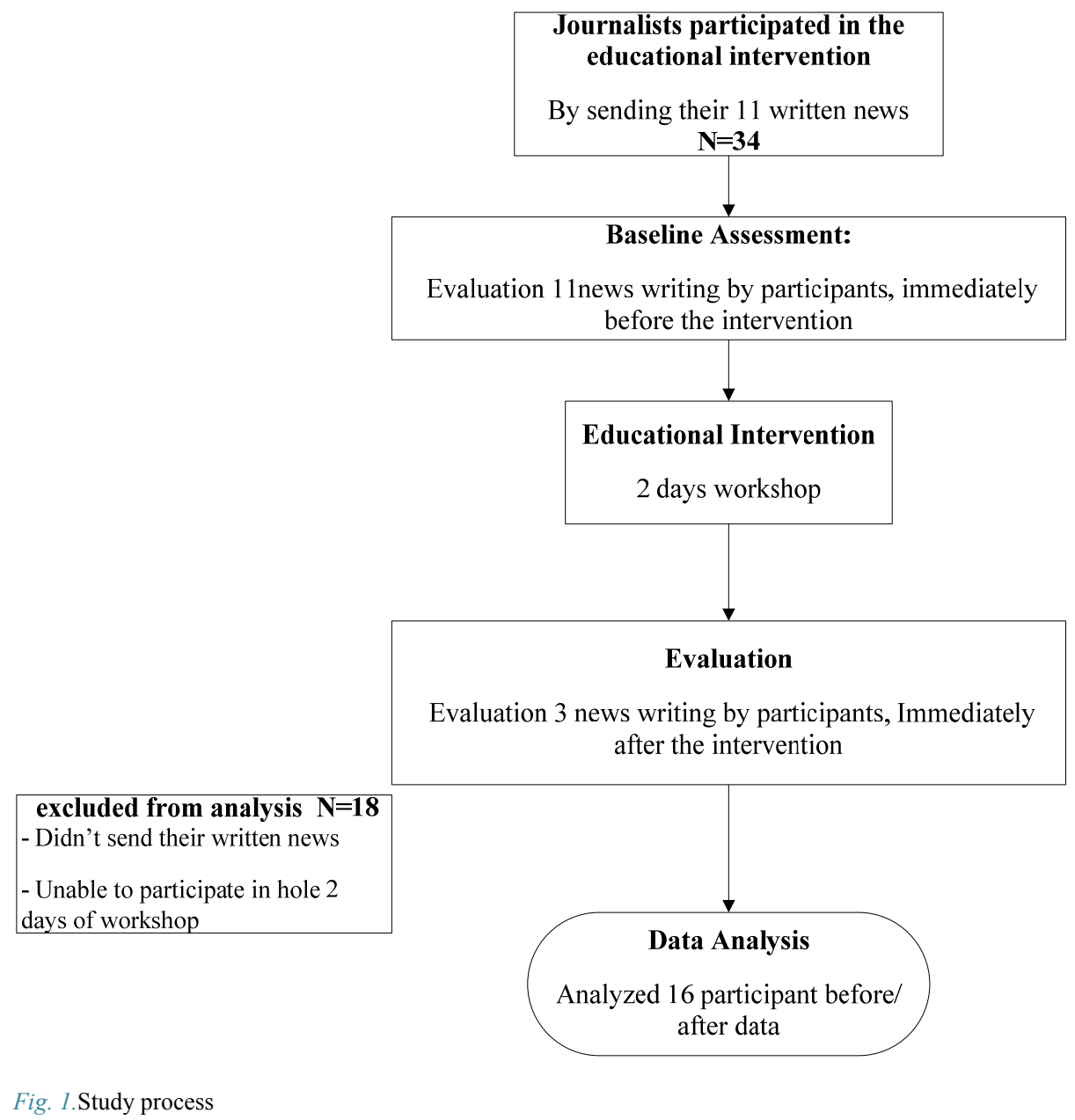




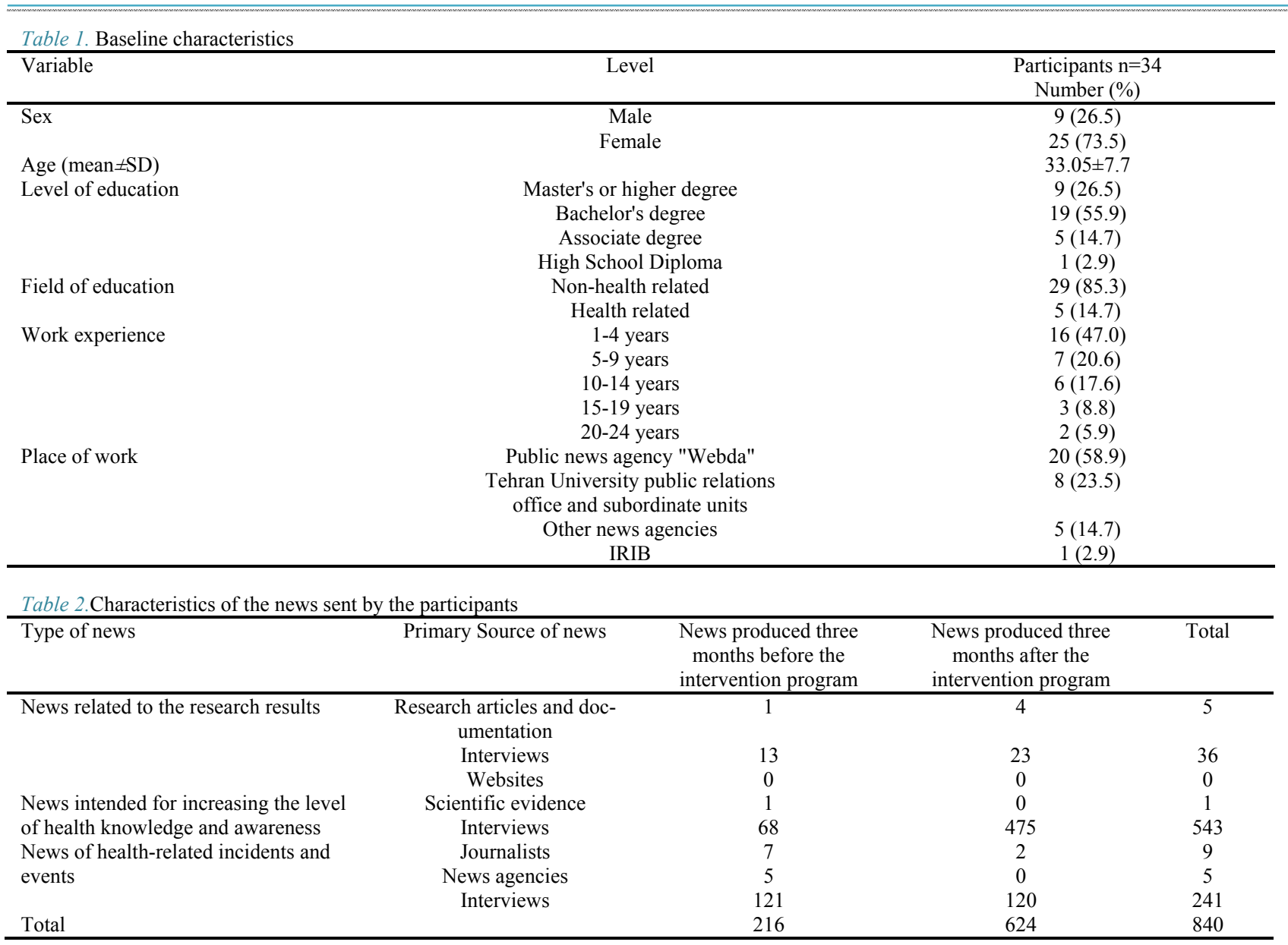

\section{Discussion}

In this study, an appropriate content for educating and empowering health news producers was prepared, and its effect on the quality of produced news was evaluated. Based on the results of this study, the provided educational intervention can increase the quality of news produced by health news producers.

The educational content in this studywas prepared by reviewing the existing literature and emphasizing the expressed needs of the health news producers. Factors such as evaluating the news source's validity, conducted research's precision, prominence of scientific findings, the magnitude of effect of the results, consequences, epidemiologic and statistical definitions, familiarity with research studies, and searching data banks were among the main themes of the educational content of HRN preparation. Most of these items have been sporadically identified by numerous studies as the health journalists' requirements to produce health news. In a study conducted in Milan, Italy, a checklist was prepared that encouraged journalists to have a scientific approach toward scientific topics and learn the necessary skills to access news sources. It pointed toward the following factors: which sources to choose, with what level of quality, how to analyze the details of the matter, and how to best translate it into the lay language (11). In 2014, Veloudakifound that the most important barriers to reporting health and medical news are misunderstanding of statistical interpretation and lack of medical training (12). Wilson also believed that health journalists need to be professionally educated in methodology, research methods, statistics and health, and pointed out that this kind of education (training) is not sufficiently available (1). An editor-in-chief of an authentic journal (PLoS) believed that health journalists have seldom received adequate education to comprehend the complexities of medical research(13). The requirements have been sporadically extracted in previous studies and researches. Preparing educational content that will cover most of these necessities can empower health news producers. In this study, the research group tried to include all the educational needs in the intervention.

The results of this study showed a 0.21 score increase in the quality of health news produced by those who took part in the educational intervention program. In this study, most participants had no prior health knowledge. This is while a health journalist's knowledge and its effect on the quality of news have been underlined in numerous studies. According to a study in Australia, professional journalists produce news of higher quality (6). Since the effect of health knowledge on the quality of produced news is evident, it seems that the 0.21 -unitincrease will be even more prominent in individuals with prior health knowledge background.

This study identified interviews as the largest source of health news. They were the source of $97.6 \%$ of the news collected by participants. This reminds us of the important 
role of health researchers and experts as factors influencing the quality of health news. However, some studies showed that lacking adequate education is not the only reason behind poor health news quality. They concluded that researchers are as responsible as journalists when reflecting inaccurate health news $(13,14)$. Therefore, it is necessary to take certain actions to improve the health journalists' level of knowledge and awareness in the context of media and their relationship with the public. It is, therefore, possible to raise the quality of health-related news by intervening in this influential group's way of work.

The fact that this study was a single-arm trial could be considered as one of its limitations. If the study was conducted as a randomized controlled trial, the findings would have been more reliable and authentic.

\section{Conclusion}

The results showed that educational intervention significantly affects the quality of HRN. Therefore, this project's researchers believe that educational interventions intended for the promotion of journalists' level of health and research knowledge can actually improve the quality of disseminated news. Furthermore, by educating other groups of individuals affecting the validity and quality of news, such as researchers, and creating a suitable context for them, in addition to educating health news, producers can increase the quality of HRN more effectively.

\section{Acknowledgments}

This study was part of Mahnaz Ashoorkhani's M.S. thesis (Designing an Educational Program for Empowering Health News Producers and Assessing Its Impact), which was supported by Tehran University of Medical Sciences (grant no: 14241-102-03-90). Also, all health news producers who lent their valuable time and participated in this study are thanked for their time and participation.

\section{Conflict of Interests}

The authors declare that they have no competing interests.

\section{References}

1. Wilson A, Bonevski B, Jones A, Henry D. Media reporting of health interventions: signs of improvement, but major problems persist. PLoS One. 2009;4(3):e4831.

2. Cassels A, Lexchin J. How well do Canadian media outlets convey medical treatment information? Initial findings from a year and a half of media monitoring by Media Doctor Canada. Open Med. 2008;2(2).

3. Kininmonth AR, Jamil N, Almatrouk N, Evans CE. Quality assessment of nutrition coverage in the media: a 6-week survey of five popular UK newspapers. BMJ Open. 2017;7(12):e014633.

4. Coleman R, Thorson E, Wilkins L. Testing the effect of framing and sourcing in health news stories. J Health Commun. 2011;16(9):941-54.

5. Ashorkhani M, Gholami J, Maleki K, Nedjat S, Mortazavi J, Majdzadeh R. Quality of health news disseminated in the print media in developing countries: a case study in Iran. BMC Public Health. 2012;12(1):627.
6. Wilson A, Robertson J, McElduff P, Jones A, Henry D. does it matter who writes medical news stories? PLoS Med. 2010;7(9):e1000323.

7. Ashoorkhani M, Golami J, Majdzadeh R. Target Audiences' Awareness and Perspectives on the Guideline on

"Dissemination of Health Research Results and Innovations". Hakim Res J 2011;14(3):165-73.

8. Vercellesi L, Minghetti P, Di Croce M, Bazzi A, Pieroni B, Centemeri $\mathrm{C}$, et al. Recommendations for health reporting: Proposal of a working paper. Health Educ J. 2010;69(1):4862.

9. Ashoorkhani M, Majdzadeh R, Nedjat S, Gholami J. Promoting the quality of health research-based news: Introduction of a tool. International Journal of Preventive Medicine. 2017;8:87. Published 2017 Nov 1.

10. Schwitzer G. How do US journalists cover treatments, tests, products, and procedures? An evaluation of 500 stories. PLoS Med. 2008;5(5):0700-4.

11. Miranda GF, Vercellesi L, Bruno F. Information sources in biomedical science and medical journalism: methodological approaches and assessment. Pharmacol Res. 2004;50(3):26772.

12. Veloudaki A, Zota D, Karnaki P, Petralias A, Saranti Papasaranti E, Spyridis I, et al. Reporting health in Europe: Situation and needs. J Commun Healthc. 2014;7(3):158-70.

13. The PLoS Medicine Editors (2008) False hopes, unwarranted fears: The trouble with medical news stories. PLoS Med 5(5): e118.

14. Lai WY, Lane T. Characteristics of medical research news reported on front pages of newspapers. PLoS One. 2009;4(7):e6103. 